\title{
Analysis of Students 'Mathematic Ability in using Open Ended Teaching Materials on Class VIII Function Relations Materials
}

\section{Ninik Diah Wulandari, Yus Mochamad Cholily, Rizal Dian Azmi}

\author{
Mathematics Education, Faculty of Teacher Training and Education, University of \\ Muhammadiyah Malang \\ E-mail: ninikdiahwulandari@gmail.com
}

\begin{abstract}
This study aims to describe the students' written mathematical communication skills in using open ended-based teaching materials in class VIII function relations material. The type of research used is descriptive qualitative. The research subjects were 5 students of class VIII E SMP. Data collection techniques in this study in the form of tests and interviews. The research results obtained by students in the category of high written mathematical communication skills have the ability to convert questions into set notations, students are quite capable of transforming mathematical information into images and students are able to use mathematical information to solve problems. Students with written mathematical communication skills have sufficient ability to convert mathematical information into set notations, students are less able to convert mathematical information into images and students are able to use mathematical information to solve problems. Students with low communication skills seen from students are unable to change questions into set notations, students are less able to convert mathematical information into images and students are unable to be able to use mathematical information to solve problems.
\end{abstract}

Keywords: mathematical communication skills, open ended-based teaching materials, relationships and functions

\section{INTRODUCTION}

Understanding the material in mathematics is important for students. According toSari, Nurochmah, Haryadi, \& Syaiturjim (2016), the ability to understand mathematics built by students themselves will be more meaningful because the math problems given will be more easily solved by students by understanding the knowledge learned.

Understanding the material in mathematics learning is directly proportional to the mathematical communication skills of students. According toUmar (2012), students need to develop mathematical communication in learning mathematics because each student should have mathematical communication skills both written and oral. Writing mathematical communication is the focus of this research. According toDina, Mawarsari \& Suprapto (2015) said that students have good written mathematical communication skills when students are able to understand the material optimally.

Many factors of students' low mathematical communication skills occur such as: 1) students lack mastery in analyzing the questions given; 2) lack of basic mathematical abilities, and 3) lack of developing talents possessed by students(Yanti, Melati, \& Zanty, 2019). Based on preliminary observations that have been made at SMPN 12 Malang, students have problems related to mathematical communication skills such as: 1) many students still cannot distinguish between writing function notations with function formulas, and 2) students forget in writing relations formed from two the set. This was confirmed byFerdiani (2015)which states that the material that is considered difficult by students during semester one is the material of relations and functions so that students' 
mathematical abilities are also very low as seen from the many children who get KKM only $45 \%$ of 28 students with KKM of 6.50 . Another opinion said that there were still often errors in answering problems in the subject of relations and functions because students had difficulty defining the concepts of relations and functions as well as a lack of understanding in the interpretation of the stages and procedures of relations and functions.(Melati, Purwasi, \& Fitriyana, 2019).

The use of teaching material is one of the important things in learning because teaching material is a component of learning that contains material to be learned by students. Teaching materials are needed by students to build mathematical communication through the activities in it(Hidayanto \& Irawan, 2013). Student Worksheet (LKPD) is one of the teaching materials that can be used.

Mathematical learning nowadays has a lot of references to the use of open ended questions. According toKadarisma (2018)states that the open ended approach is able to improve students' mathematical communication skills because students are required to be active and creative in communicating material and are more clever in explaining mathematical ideas and situations. This is confirmed byJasmaniah, Fachrurazi, \& Yeni (2015) argues that open ended-based problem solving teaching materials can develop reasoning even though it is not yet significant so that an increase in reasoning will also have an impact on improving mathematical communication owned as seen from an increase in each test score. S. Subekti (2016) also states that an increase in students' mathematical communication skills is caused because students are given open ended questions, namely questions with many ways to solve or questions with many correct answers.

The main problem in this research is how the students' mathematical communication skills in using open ended LKPD teaching materials on class VIII function relations material. The purpose of this study is to describe the students' mathematical communication skills if in mathematics learning using open ended based LKPD teaching materials.

\section{RESEARCH METHODS}

This research was carried out in SMP Negeri 12 Malang, located at Jl. Slamet Supriadi No.49, Bandungrejosari, Sukun District, Malang City with a time of research conducted in the even semester of the 2019/2020 school year. The type of research used is descriptive with a qualitative approach. The subjects of this study took 5 students with different written mathematical communication skills, namely low, medium and high from class VIII at 12 State Junior High School Malang.

Researchers conducted data collection techniques with tests and interviews. The use of tests to obtain more accurate data about students' written communication skills on the subject matter of relations and functions. While the instruments used by researchers are tests and interviews.

The test used in this study is in the form of an open ended-based question item in the teaching material. The use of description tests is expected to make students able to express ideas / ideas in written form. The research instrument in this test contains three questions about relation material and function, the results of which are obtained based on indicators. The student's written communication indicators in the material relation function that can be seen when students are able to change the questions into notations on the material relations and functions, students are able to change mathematical information into the form of pictures in the material relation functions and students are able to use 
mathematical information to solve problems in the relation material function. While the interview guidelines are adjusted to the indicators that have been made, namely: 1) students are able to mention the information obtained from the questions given; 2) students are able to know the notation writing; 4) students are able to change the information obtained into images; 4) students are able to know the ways used to solve problems, and (5) students are able to explain the results of answers.

Data analysis technique is a continuation of data collection techniques that have been described. Data analysis technique aims to answer the problem formulation in a study that has 4 aspects in qualitative data analysis(Sugiyono, 2015)namely: 1) data collection by conducting a written test of three questions and interviews with students; 2) data reduction by categorizing into three groups that have been obtained based on indicators of mathematical communication skills written; 3) presentation of data obtained from the results of written test answers and interviews conducted by students will then be described in the form of sentences or descriptions, and 4) drawing conclusions containing a brief description of the results of mathematical communication skills analysis written. The following categories are the percentage of mathematical communication skills written in Table 1.

Table 1. Percentage Categories of Mathematical Writing Communication Skills

\begin{tabular}{ccc}
\hline No. & Percentage $(\%)$ & Category \\
\hline 1 & $72 \leq x \leq 100$ & High \\
\hline 2 & $33<x<72$ & Is \\
\hline 3 & $0 \leq x \leq 33$ & Low \\
\hline
\end{tabular}

\section{RESULTS AND DISCUSSION}

Based on the results of research that has been carried out in SMP Negeri 12 Malang will be described in this chapter about students' written mathematical communication in using open ended LKPD teaching materials on the material relations of class VIII functions. The study was conducted 2 times on 18 February and 20 February 2020. The first study was conducted tests on students using open ended LKPD teaching materials to obtain the desired data and the second study was interviews. The interview in this study aims to support students' answers so that the results obtained are more accurate.

Table 2. Categories of Mathematical Writing Communication Capabilities Class VIII students

\begin{tabular}{ccc}
\hline \multirow{2}{*}{ Category } & \multicolumn{2}{c}{ Student } \\
\cline { 2 - 3 } & total & Percentage \\
\hline High & 9 & $40.91 \%$ \\
Is & 12 & $54.55 \%$ \\
Low & 1 & $4.55 \%$ \\
\hline
\end{tabular}

Based on table 2, seen from the total students of class VII-E as many as 22 students there are 9 students with high mathematical communication skills, 12 students with medium mathematical communication skills and 1 student with low mathematical communication skills.

A. Mathematical Communication Skills for Students in High Categories

1. Students with the code name DLD 
Based on the analysis of the results of students' answers with the code name DLD, these students are classified as having mathematical communication skills with a high category of $96.30 \%$.

In questions number 1 and 2 students are able to write the set notation in the form of tabulation correctly and correctly, students are able to draw arrow diagrams clearly and precisely seen from the ability of students to pair between the two sets with arrows in accordance with relationships that can be formed and are able to state the relationships that are formed, and students are able to solve problems using mathematical information that has been obtained previously.

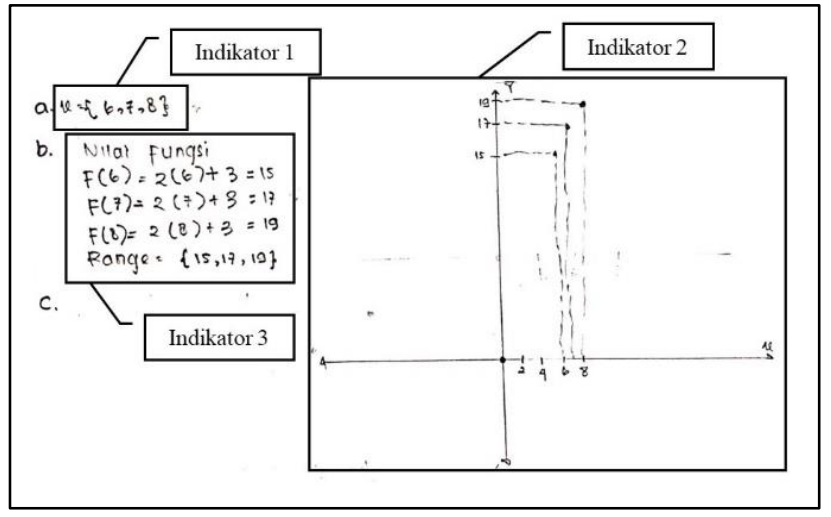

Figure 1. Answer number 3 students with the code name DLD

Namun in question number 3 students are not quite right in describing a graph. Judging from the results of students' answers that the scale used to determine the points is not the same length and students do not draw straight lines to connect each coordinate point on the function graph.

\section{Students with the code name IK}

Based on the analysis of the results of students' answers with the code name IK, these students are classified as able to write mathematical communication with a high category of $88.89 \%$.

In questions number 1 and 2 students are able to write the set notation in the form of tabulation correctly and correctly, students are quite able to draw arrow diagrams clearly and precisely seen from the ability of students to pair between the two sets with arrows accordingly but students forget to write a relation formed from two sets, and students are able to solve problems using mathematical information that has been obtained previously. 


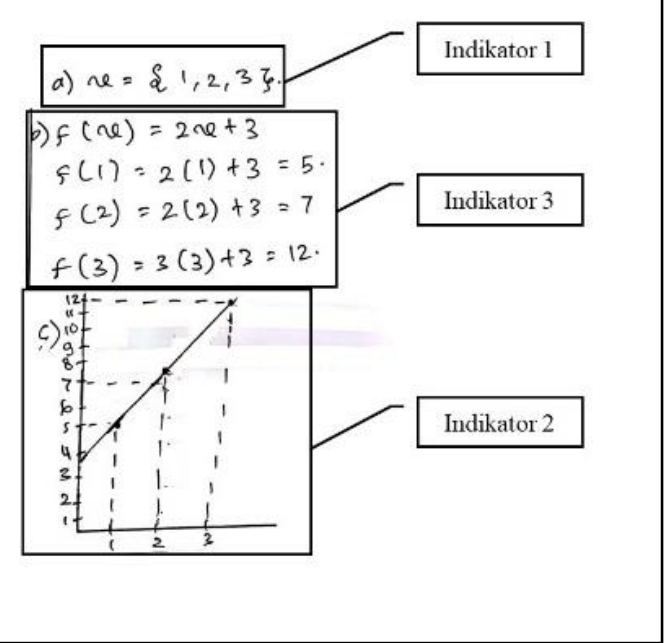

Figure 2 Answer number 3 students with the code name IK

Namun in question number 3 students are less able to draw a graph of the function seen from the answers of students who do not write variables to determine the axis and the axis and students also draw lines for lines that attach points to which means the length of the line is limited. $x y x f(x)$

B. Mathematical Communication Skills of Students in the Medium Category

1. Students with the code name KDAPB

Based on the analysis of the results of students' answers with the code name KDAPB, these students are classified as writing mathematical communication abilities with a moderate category of $62.96 \%$.

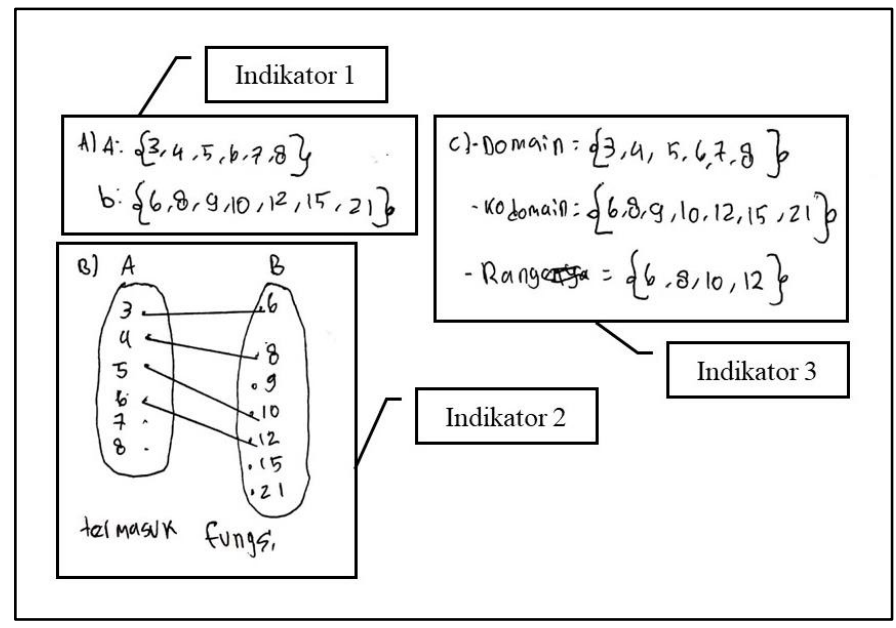

Figure 3. Answer number 1 students with the code name KDAPB

Based on Figure 3, in indicator 1 students are less able to write the set notation. Students should write using capital letters and continue with an equal sign (=) like and. This happened because $A=\{3,4,5,6,7\} B=\{6,8,9,10,12,15,21\}$ students forget and assume that writing the correct notation is enough with the use of curly braces. In indicator 2, students are able to convert information from sets and sets into picture form. 
However, on the arrow diagrams made by students do not write the relations formed from the two sets. In indicator 3 , students are able to solve problems using mathematical information beforehand by writing the domain, code and range correctly. $A B$

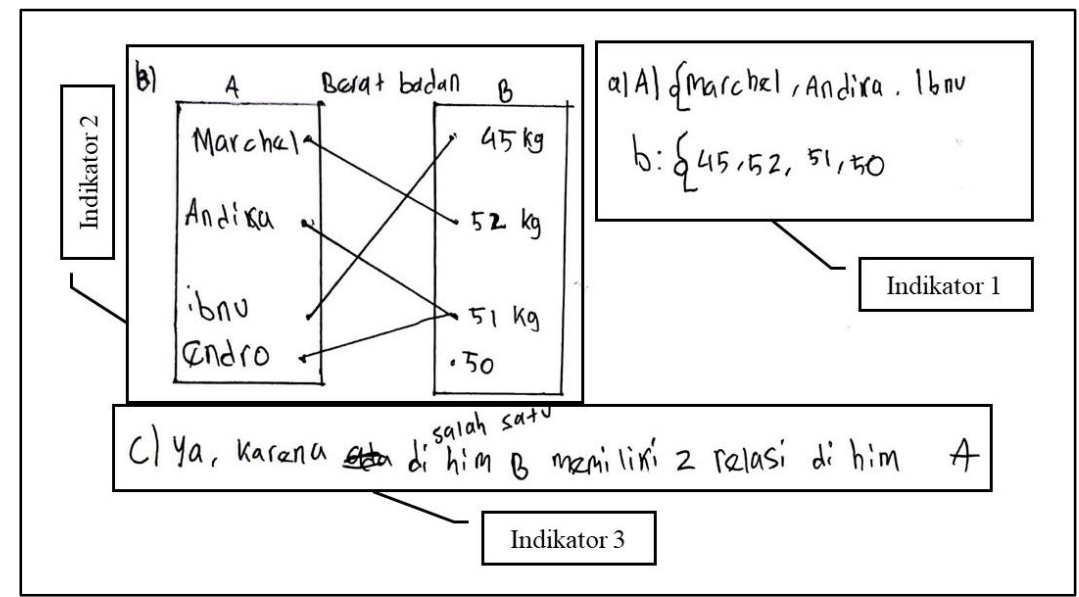

Figure 4 Answer number 2 students with the code name KDAPB

In question number 2 , the same is the case with answer number 1 , iIndicator 1 students are less able to write the set notation because students do not write the set notation correctly. On iindicator 2,students are quite able to draw an arrow diagram with the relationships formed by these students based on the sets and sets that have been made by students before. This happens because students do not draw lines with arrows to show the relationship in the arrow diagram. On i $A B$ indicator 3 , students are not able to solve the questions given based on the relationships that have been formed by these students because students cannot distinguish functions and not functions based on understanding.

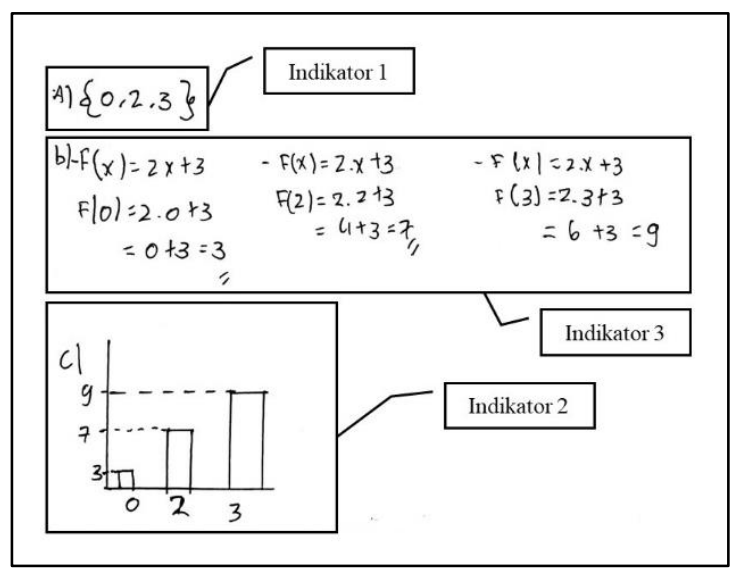

\section{Figure 5 Answer number 3 students with the code name KDAPB}

On the problem number 3 , indicator 1 students are less able to change the questions into notation set because students do not write variables $x$ which represents these three positive integers. In indicator 3 , students are able to determine the value of the function by means of substitution and the results obtained from the work are also correct. In indicator 2, students are not able to draw a graph of functions because students draw a bar diagram of the answer. $f(x)=2 x+3$ 


\section{Students with the code name MRAS}

Based on the analysis of the results of students' answers with the code name MRAS, these students are classified as having mathematical communication skills with a moderate category of $59.26 \%$.

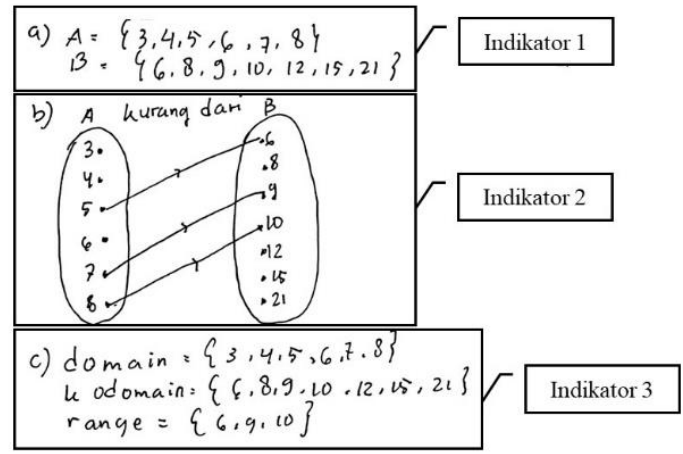

\section{Figure 6. Answer number 1 students with the code name MRAS}

Based on Figure 6, in indicator 1 students are able to write the set notation correctly and the correct set member in the form of tabulation or register. In indicator 2, students are quite capable in drawing arrow diagrams but students are not quite right in expressing a relation, should the relationship formed by students is "less than". In indicator 3, students are quite capable of solving problems based on prior mathematical information. Students are able to determine the domain and code of two sets. But students are not quite right in determining the range of relations formed by the set and the set. $A B$

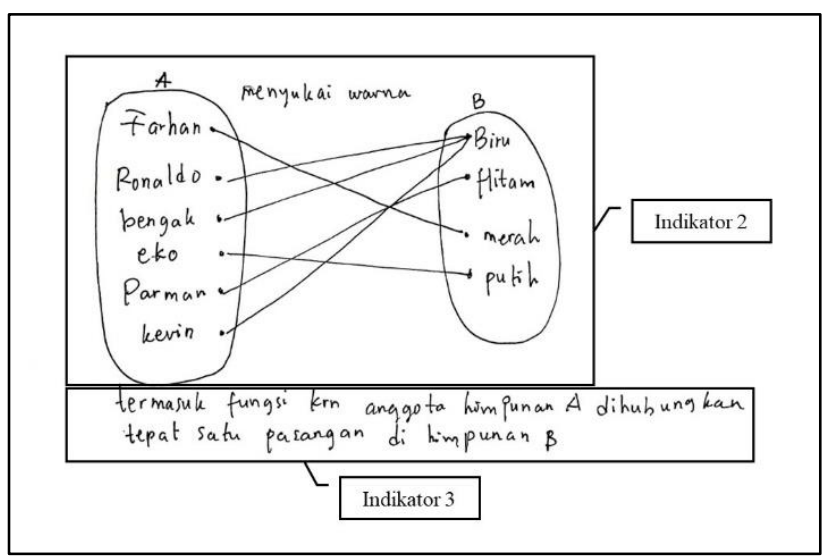

Figure 7. Answer number 2 students with the code name MRAS

Based on Figure 7, the indicator 1 students do not write the set $A$ and the set first is in the form of the set notation because the members of the set and the members of the set have entered into the form of an arrow diagram that is made so that students feel no need to write it back into the form of set notation. In indicator 2, students are able to draw relationships in the form of arrow diagrams to determine the relationship between the set and the set because students do not draw arrows as a pointer to a line to connect the two sets. In indicator 3, students are able to solve problems from previous information. Based 
on the relationships formed by students, the relationship is a function so that the students' answers are correct and students give the right reasons. $B A B A B$

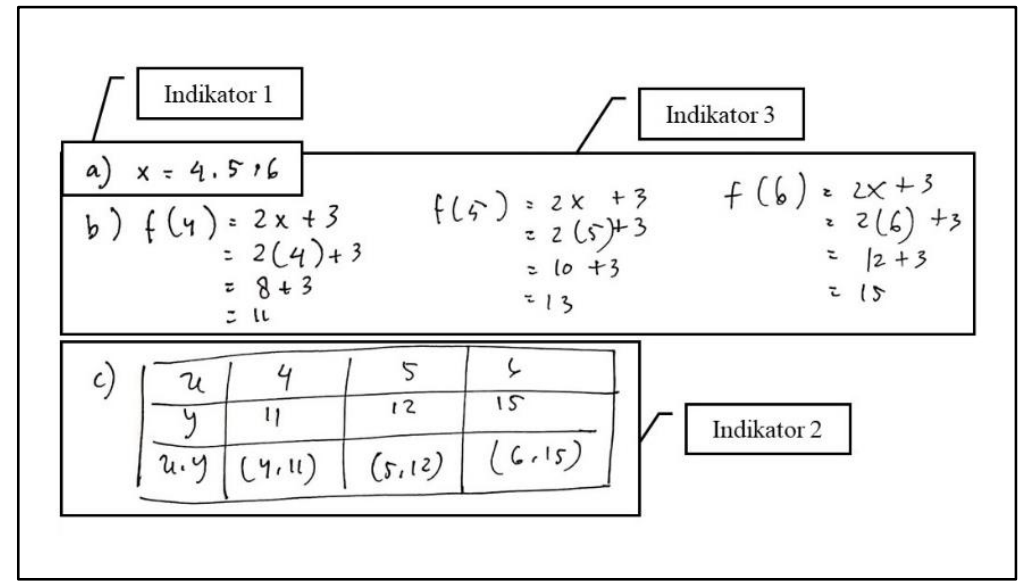

\section{Figure 8 Answer number 3 students with the code name MRAS}

Based on Figure 8, in indicator 1 students are quite able to change the questions into the form of set notation but should write the set notation using curly braces as a sign to indicate the set members. In indicator 3, students are able to determine the value of the function by means of substitution and the results obtained from the work are also correct. In indicator 2, students are not able to draw a graph of functions by pairing a point at. Students only draw tables to make it easier to pair points and. The tables drawn by students in the answers are able to help students to make it easier to draw graphs of functions. $f(x)=2 x+3 x f(x) x y$

\section{Student Mathematical Communication Skills of Low Category}

1. Students with the code name ESU

Based on the analysis of the results of students' answers with the code name ESU, these students are classified as having mathematical communication skills with a low category of $29.63 \%$.

In questions number 1 and 2, in indicators 1 and 3 students do not answer the questions given. But on indicator 2, students draw arrow diagrams quite well but students do not write down the relations formed from sets and sets. $A B$

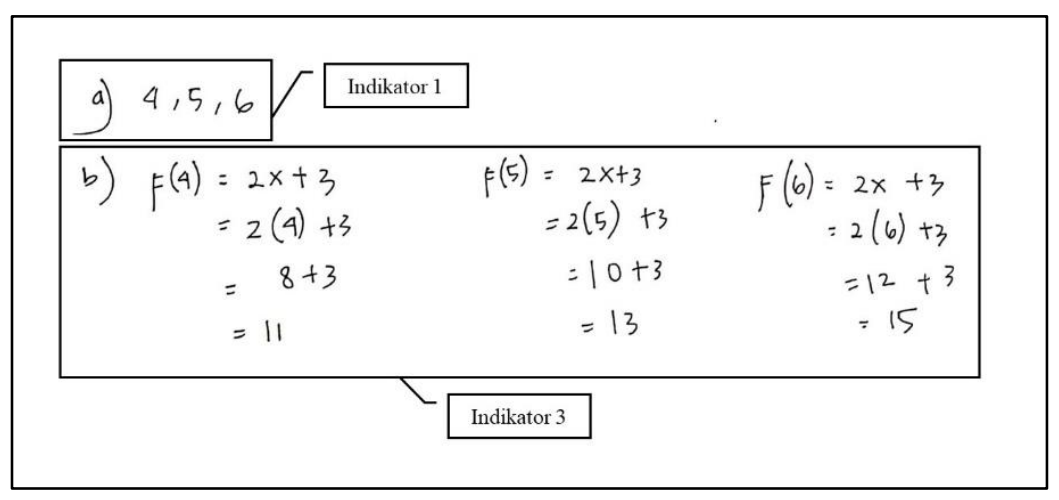

Figure 9. Answer number 3 students with the code name ESU 
Based on Figure 9, in indicator 1 students are able to choose three values that represent by any member of positive integers but students do not write it in the form of set notation. $x x$. In indicator 3 , students are able to determine the value of the function by means of substitution and the results obtained from the work are also correct. In indicator 2, students are not able to complete the problem to illustrate the requested function graph because students do not know the intended function graph of the problem. This can be seen from the answers of students who do not write a graph of the function in the place provided answers. Based on the results of interviews conducted, students do not know how to draw a function graph $f(x)=2 x+3$.

In students with mathematical communication skills high category can be reviewed from: 1) students are able to change the questions into set notations appropriately in questions number 1,2 and $3 ; 2$ ) students are able to convert mathematical information into pictures, such as students drawing arrows diagrams to state a relation and drawing a graph of functions by pairing points at $\mathrm{x}$ ) but there are still students who are less precise in describing graphs of functions, and 3) students are able to use information mathematically to solve the problem given in problems number 1,2 and 3. This is in line with research conducted by $x f$ (Mandasari \& Chandra (2018)which states that students with written mathematical communication skills with high categories can be reviewed from: 1) students are able to state mathematical situations or information in the form of symbols or languages in full as writing is known and asked correctly; 2) students are able to change a mathematical information in the form of venn diagrams and write symbols as information in venn diagrams; 3) students are able to choose and use mathematical information or pictures to solve problems in problems number 2 and number 3, and 4) students are able to write the calculation process completely and correctly. Previous studies that are also in line with the results obtained were conducted byPermata, Kartono \& Sunarmi (2015)which states that students with high mathematical communication skills tend to be able to achieve indicators expressing, demonstrating, describing and interpreting mathematical ideas.

Students with mathematical communication skills in the category can be reviewed from: 1) students are quite capable of turning questions into set notations in questions number 1 and 3, even though in interviews conducted students are able to change questions into set notations. But in question number 2, there are still students who do not write the set notation based on the questions given; 2) students are able to convert mathematical information into pictures, like students are able to draw in the form of arrow diagrams in questions number 1 and 2 but students still forget to write down the relation formed from these two sets. In problem number 3, students are not able to convert mathematical information into graphical functions, although in interviews students realize that the answers are not quite right and understand how to draw graphs of functions, Mandasari \& Chandra (2018)which states that students with mathematical communication skills are categorized as being written in terms of: 1) students are able to state mathematical situations or information in the form of languages such as writing known and asked on problems number 2 and number $3 ; 2$ ) students are able to change a mathematical information in the form of a venn diagram and write symbols as information that is in the venn diagram in problem number 2 but in problem number 3 students have not been able to draw a venn diagram correctly, and 3) students are able to choose and use mathematical 
information or pictures to solve the calculation problem in problem number 2 but in problem number 3 students have not been able to write the calculation process correctly.

In students with mathematical communication skills of low category can be seen from: 1) students are not able to change the questions into notation so that students do not write the notation of sets of two sets. This is different from the research conducted byMandasari \& Chandra (2018)which states students are able to state the situation or mathematical information in the form of symbols or languages in full, such as writing known and asked correctly in problem number 2 and number 3 ;2) students are quite capable of transforming mathematical information into drawing, as in questions number 1 and 2 students are able to draw arrow diagrams but students do not write down the relation formed from the two sets. In question number 3, students cannot draw graphs of functions, 3) students are unable to use mathematical information to solve problems in questions number 1 and 2 so students do not write answers to the questions asked even though in problem number 3 students are able to solve problems in determining function value. The results of previous studies that are in line with the results of this study were conducted byZulfah \& Rianti (2018)which states that students with low mathematical communication skills are still weak in making mathematical models as well as the low ability to reflect graphics into mathematical ideas. But most students have good skills in computing or calculation.

\section{CONCLUSION}

Based on the analysis results of mathematical communication skills of students in SMP Negeri 12 Malang obtained 3 categories of mathematical communication skills that are high, medium and low. Students have high mathematical communication skills because students are able to turn problems into notations, students are able to convert mathematical information into images and students are able to use mathematical information to solve problems. Students have moderate mathematical communication skills because students are able to convert questions into notation form but students are not quite right in writing set notations, students are less able to convert mathematical information into arrows diagram images by not writing relationships formed from setsA and set Band students are less able to draw graphs of functions and students are able to use mathematical information to solve problems. Whereas students have low mathematical communication skills because students are not able to convert questions into notation so students do not write answers, students are less able to convert mathematical information into arrow diagram shapes by not writing relationships formed from setsA and the set and students are not able to draw graphs of functions and students are less able to use mathematical information to solve problems.

\section{REFERENCES}

Dina, A., Mawarsari, VD, \& Suprapto, R. (2015). Implementation of 2013 Curriculum on Learning Tools Discovery Learning Model Scientific Approach to Mathematical Communication Capabilities of Vocational Geometry Materials. Journal of Mathematics Education Work, 2 (1). Retrieved from https://jurnal.unimus.ac.id/index.php/JPMat/article/view/1830

Ferdiani, RD (2015). Two Stay Two Stray Learning to Improve Mathematical 203 
Communication on Material Relations and Functions in Al Inayah Purwosari Pasuruan Middle School. Journal of Educational Inspirations, 5 (2), 715-721. https://doi.org/10.1017/CBO9781107415324.004

Hidayanto, T., \& Irawan, E. (2013). Development of Mathematic Education Realistic Based Learning Materials To Build Mathematical Communication Capabilities of Grade VIII Middle School Students on Function Material. Malang State University, $13(3), 2$.

Jasmaniah, Fachrurazi, \& Yeni, EM (2015). Open-ended Problem Solving Based Learning Materials in Mathematics Learning to Develop Students' Reasoning Ability in PGsd. Journal of Educational Research, 15 (3).

Kadarisma, G. (2018). Application of Open-Ended Approach in Improving Communication Capabilities of Middle School Students. Scientific Journal of Mathematics Education, 1 (2).

Melati, RS, Purwasi, LA, \& Fitriyana, N. (2019). Development of Student Worksheets Based on the Open Ended Approach on the Relationship Materials and Functions of Class VIII Students of SMP Negeri 2 Lubuklinggau in the 2018/2019 Academic Year. Concept and Communication, null (23), 301-316. https://doi.org/10.15797/concom.2019..23.009

Sari, DP, Nurochmah, N., Haryadi, H., \& Syaiturjim, S. (2016). Improving the Ability of Mathematical Understanding Through the Student Teams Achivement Division Learning Approach. Journal of Mathematics Education Research, 3 (1), 16. https://doi.org/10.21831/jrpm.v3i1.7547

Subekti, S. (2016). Comparative Effectiveness of Open-Ended and GI Approaches Judging from Communication, Mathematical Problem Solving and Learning Motivation. Pythagoras: Journal of Mathematics Education, 8 (2), 204-212. https://doi.org/10.21831/pg.v8i2.8950

Sugiyono (2015). Quantitative, Qualitative, and R\&D Research Methods. Bandung: Alfabeta.

Umar, W. (2012). Building Mathematical Communication Skills in Mathematics Learning. Infinity Journal, 1 (1), 1. https://doi.org/10.22460/infinity.v1i1.2

Yanti, RN, Melati, AS, \& Zanty, LS (2019). Analysis of Understanding Ability and Mathematical Communication Skills of Junior High School Students in Material Relations and Functions. 3 (1), 209-219. 